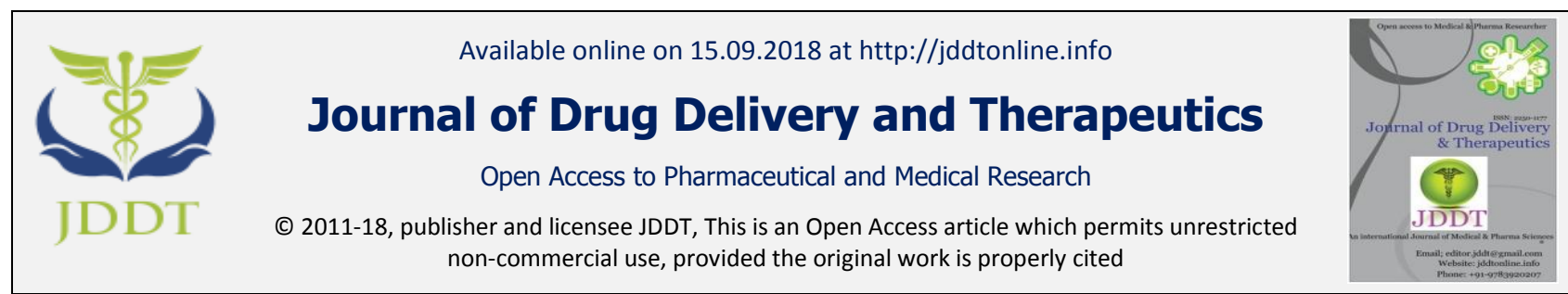

Open $\mathcal{O}_{\text {Access }}$

Review Article

\title{
SOLUBILITY ENHANCEMENT OF POOR WATER SOLUBLE DRUGS BY SOLID DISPERSION: A REVIEW
}

\author{
S.D. Mankar ${ }^{1 *}$, Punit R. Rachh ${ }^{2}$ \\ ${ }^{1}$ Department of Pharmaceutics, Pravara Rural College of Pharmacy, Loni, 413736, India \\ ${ }^{2}$ Department of Pharmaceutical Sciences, Bhagwant University, Rajasthan. India
}

\begin{abstract}
The solubility behavior of drugs remains one of the most exigent aspects in formulation development. With the advent of combinatorial chemistry and high throughput screening, the number of poorly water soluble compounds has dramatically increased. Among all the newly discovered chemical entities, about $40-45 \%$ drugs fail to reach market due to their poor water solubility. Because of solubility problem, bioavailability of drugs gets affected and hence solubility enhancement becomes necessary. Solid dispersions have attracted considerable interest as an efficient means of improving the dissolution rate and hence the bioavailability of drugs. Therefore, the application of this technique proves to be an important stratagem for pharmaceutical companies. However, the in - depth knowledge of the solid dispersion is desired for the scale up of formulation, from laboratory scale to industrial scale. There are various methods available to improve the solubility of the new drug in which solid dispersion emerged promising. A Solid dispersion generally composed of two components- the drug and the polymer matrix. Hence, this approach is expected to form a basis for the commercialization of many poorly water-soluble and water-insoluble drugs in their solid-dispersion formulations in the near future. This article reviews the various preparation techniques, carriers used, advantages and limitations of solid dispersions and compiles some of the recent advances.
\end{abstract}

Keywords: Bioavailability, Solid Dispersion, Hydrophilic carriers, Polyethylene glycol.

Article Info: Received 08 Aug, 2018; Review Completed 30 Aug 2018; Accepted 31 Aug 2018; Available online 15 Sep 2018

\section{Cite this article as:}

Mankar SD, Rachh PR, Solubility enhancement of poor water soluble drugs by solid dispersion: a review, Journal of Drug Delivery and Therapeutics. 2018; 8(5):44-49 DOI: http://dx.doi.org/10.22270/jddt.v8i5.1887

*Address for Correspondence:

S.D. Mankar, Department of Pharmaceutics, Pravara Rural College of Pharmacy,Loni, 413736.

\section{INTRODUCTION}

Solubility is a significant physicochemical factor affecting absorption of drug and its therapeutic effectiveness. Formulation development would lead to be failure if drug having poor aqueous solubility. The venture to improve the solubility and dissolution of hydrophobic drugs remain one of the dificult tasks in drug development. Several methods have been introduced to triumph over this problem. ${ }^{\mathbf{1}}{ }^{2}$

Various methods to increase the solubility of drugs are available such as solid dispersion, self emulsifying drug delivery, Liquisolid techniques etc, in which drug in solution state or dissolved drug is adsorbed over insoluble carriers ${ }^{3-6}$
Model list of Essential Medicines of the World Health Organization (WHO) has assigned BCS (Biopharmaceutics Classification System) classification on the basis of data available in the public domain. Out of 130 orally administered drugs on the WHO list, 61 could be classified with certainty.

$84 \%$ of these drugs belong to class I (highly soluble, highly permeable)

$17 \%$ to class II (poorly soluble, highly permeable)

$39 \%$ to class III (highly soluble, poorly permeable) and

$10 \%$ to class IV (poorly soluble, poorly permeable) 
The term solid dispersion refers to a group of solid products consisting of at least two different components, a hydrophilic matrix and a hydrophobic drug. The drug can be dispersed molecularly, in amorphous particles (clusters) or in crystalline particles ${ }^{7}$. Pharmaceutical polymers are used to create this matrix and their selection is based on many factors, including physicochemi8al (e.g. drug-polymer miscibility and stability) and pharmacokinetic (e.g. rate of absorption) constraints . Fig. 1 categorizes various possible categories of solid dispersions. The solid-dispersion components consist mainly of active pharmaceutical ingredients (API), the polymer, plasticizers, stabilizers, and other agents.

Solid dispersion systems can increase dissolution rate and bioavailability of water insoluble drugs as when these are exposed to aqueous media, the carrier dissolves, and the drug is released as very fine colloidal particles. This greatly reduces particle size and increases surface area, which results in improved dissolution rates and per oral absorption. Furthermore, no energy is required to break up the crystal lattice of a drug during the dissolution process. Drug solubility and wettability may be increased by surrounding hydrophilic carriers ${ }^{9}$,

10 This approach has been used for a variety of poorly soluble drugs such as nimesulide, ketoprofen, tenoxicam, nifedipine, nimodipine, ursodeoxycholic acid, carbamazepine, celecoxib, carvedilol ${ }^{5}$ and albendazole. ${ }^{11}$

\section{Advantages of Solid Dispersion}

Solid dispersions are obtained by separate technological processes that are to disperse pharmacologically active component in a carrier or matrix in the solid state, in order to improve the solubility and increase the rate of dissolution, which, in turn, modulates the therapeutic action due to increased bioavailability ${ }^{4,12,13}$. They have also been used to increase the chemical stability of drugs in solution or suspension ${ }^{14}$.

The first generation of SD was prepared employing crystalline carriers. These carriers include sugars and urea, which have in SD disadvantages crystal formation, which, being thermodynamically more stable, they do not release the drug with the desired speed ${ }^{15}$.

Solid dispersions can be used as formulation vehicle to facilitate the preclinical safety and early clinical studies on new chemical entities with very low aqueous solubility. It provides a means to rapidly assess the safety and efficacy profile of the drug substance that may be otherwise difficult to obtain.

\section{Disadvantages of Solid Dispersion ${ }^{2,4,16}$}

Moreover, most of the polymers used in solid dispersions can absorb moisture, which may result in phase separation, crystal growth or conversion from the amorphous to the crystalline state or from a metastable crystalline form to a more stable structure during storage. This may result in decreased solubility and dissolution rate. demerits of solid dispersions is their poor scale-up for the purposes of manufacturing.

\section{MECHANISM OF SOLID DISPERSION}

The formulations of solid dispersions results into reduction in particle size, improved wettability and enhancement of the dispersibility of the drug, thereby markedly improving the dissolution rate. The suggested mechanism behind this tremendous increase in dissolution rate may include: ${ }^{\mathbf{1 7}}$

- Partial transformation of crystalline drug to the amorphous state or altering the crystalline morphology

- Formation of solid solution

- Formation of complexes

- Intimate mixing of the drug with hydrophilic excipients

- Reduction of aggregation and agglomeration

- Improved wetting of the drug and solubilization of drug by the carrier at the diffusion layer.

\section{TYPES OF SOLID DISPERSIONS}

\section{Eutectic mixtures $^{18,19}$}

A simple eutectic mixture consists of two compounds which are completely miscible in the liquid state but only to a very limited extent in the solid state. It is prepared by rapid solidification of fused melt of two components that show complete liquid miscibility but negligible solid-solid solution

\section{Amorphous precipitation in crystalline matrix ${ }^{20,21}$}

This is similar to simple eutectic mixtures but only difference is that drug is precipitated out in an amorphous form.

\section{Solid solution $^{22}$}

Solid solutions are comparable to liquid solutions, consisting of just one phase irrespective of the number of components. In the case of solid solutions, the drug's particle size has been reduced to its absolute minimum viz. the molecular dimensions and the dissolution rate is determined by the dissolution rate of the carrier. Classified according to their miscibility (continuous versus discontinuous solid solutions) or second, according to the way in which the solvate molecules are distributed in the solvendum (substitutional, interstitial or amorphous).

\section{Continuous solid solutions}

In a continuous solid solution, the components are miscible in all proportions. Theoretically, this means that the bonding strength between the two components is stronger than the bonding strength between the molecules of each of the individual components. Solid solutions of this type have not been reported in the pharmaceutical world till date.

\section{Discontinuous solid solutions ${ }^{22}$}

In the case of discontinuous solid solutions, the solubility of each of the components in the other component is limited. Due to practical considerations, it has been suggested by Goldberg et al. that the term 
'solid solution' should only be applied when the mutual solubility of the two components exceeds $5 \%$.

\section{Substitutional solid dispersions ${ }^{23}$}

Substitution is only possible when the size of the solute molecules differs by less than $15 \%$ or so from that of the solvent molecules. Classical solid solutions have a crystalline structure, in which the solute molecules can either substitute for solvent molecules in the crystal lattice or fit into the interstices between the solvent molecules.

\section{Interstitial solid solutions ${ }^{24,25}$}

In interstitial solid solutions, the dissolved molecules occupy the interstitial spaces between the solvent molecules in the crystal lattice. Solute molecule diameter should be less than 0.59 times than that of solvent molecular diameter.

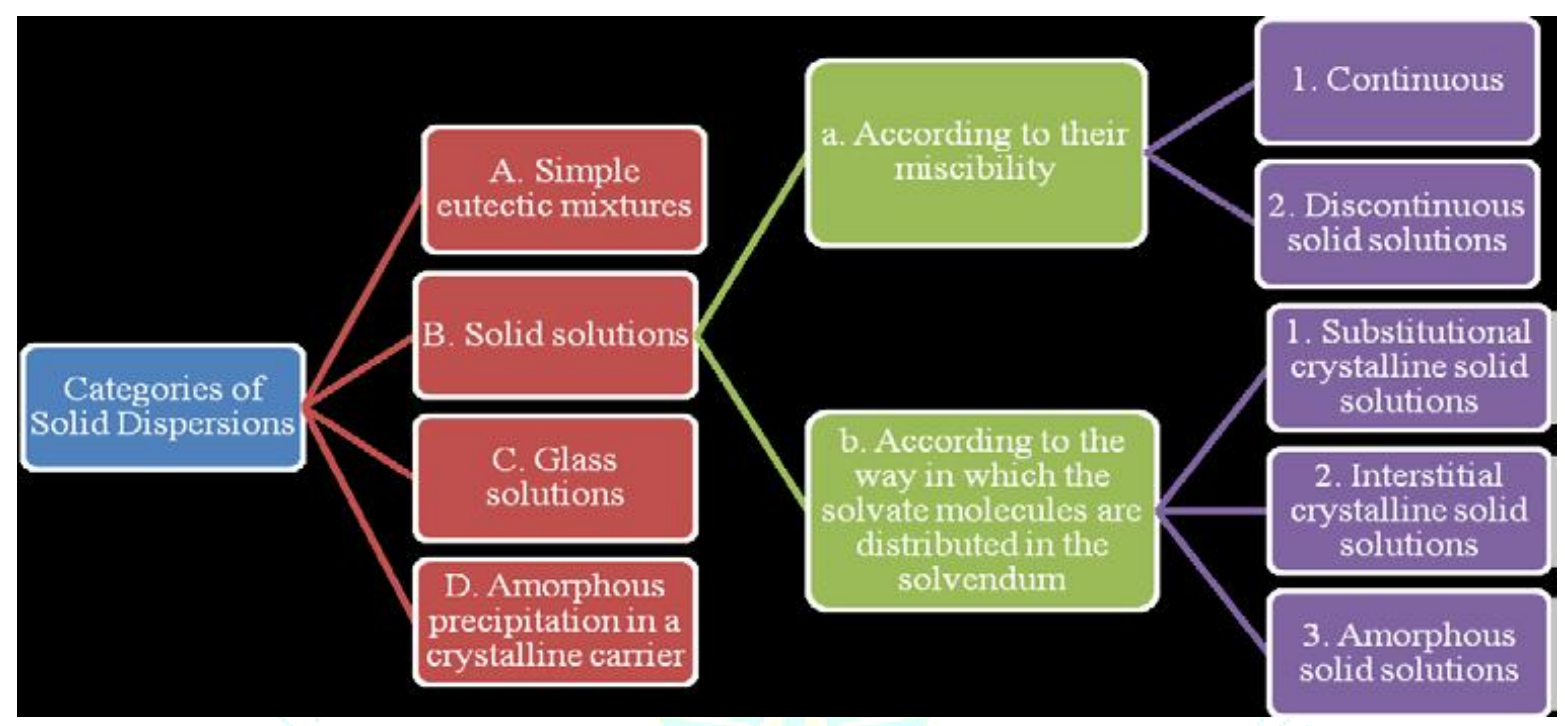

Figure 1: Categories of solid dispersion ${ }^{2}$

\section{METHODS OF SOLID DISPERSION}

Various methods have been developed for preparation of solid dispersions, these methods deal with the challenge of mixing a matrix and a drug, preferably on a molecular level, while matrix and drug are generally poorly miscible. During many of the preparation techniques, demixing (partially or complete), and formation of different phases is observed. Phase separations like crystallization or formation of amorphous drug clusters are difficult to control and therefore unwanted.

The brief description of the methods is as follows:

\section{Kneading Method}

In this method, the polymer and drug are mixed by geometric dilution. The mixture is malaxada with adding the amount of solvent minina (equivalent to $30 \%$ of the post of weight) in order to obtain a moist consistency. Industrially, a mixture of components is performed in a malaxadora, and in this case, required some adjustments in the methodology used, initially at the level bench, which can cause some modifications of the physical and chemical characteristics and pharmacotechnical the product. The drying of the material can be done in an oven or directly in malaxadora followed by pulverization to standardize the size particle. Due to the simplicity, the high throughput and the scale transposition facility, this method is the most widely used in the pharmaceutical industry ${ }^{26}$.

\section{Solvent melting method}

Accurately weighed drug is dissolved in organic solvent. The solution is incorporated into the melt of mannitol and cooled suddenly and mass is kept in desiccator for complete drying. The solidified mass is crushed, pulverized and passed through sieve. This technique possesses unique advantages of both the fusion and solvent evaporation methods. From a practical standpoint, it is only limited to drugs with a low therapeutic dose (less than $50 \mathrm{mg}$ ). ${ }^{27}$

\section{Spray-Drying Method}

Drug is dissolved in suitable solvent and the required amount of carrier is dissolved in water. Solutions are then mixed by sonication or other suitable method to produce a clear solution, which is then spray dried using spray dryer. $^{28}$

\section{Method supercritical fluid}

The process of supercritical fluid has emerged as an alternative method to the solvent method, forming small particle size precipitation and low organic matter content, with also better flow. Powder flowability is important when commercialization of the process is desired $^{35}$. Carbon dioxide is currently We used this technique due to the advantages associated with its use, as a non - toxic gas, non - flammable, inexpensive and low critical temperature, making it attractive in the processing of heat sensitive drugs and the process solvent removal extremely controlled ${ }^{13}$. Although the results promising described in the literature, is a 
technique still Experimental and having an initial cost very high $^{29}$.

\section{Co-grinding method}

Physical mixture of drug and carrier is mixed for some time employing a blender at a particular speed. The mixture is then charged into the chamber of a vibration ball mill steel balls are added. The powder mixture is pulverized. Then the sample is collected and kept at room temperature in a screw capped glass vial until use. Ex. chlordiazepoxide and mannitol solid dispersion was prepared by this method. ${ }^{30}$

\section{Gel entrapment technique}

Hydroxyl propyl methyl cellulose is dissolved in organic solvent to form a clear and transparent gel. Then drug for example is dissolved in gel by sonication for few minutes. Organic solvent is evaporated under vacuum. Solid dispersions are reduced in size by mortar and sieved. $^{31}$

\section{Melting /Fusion method}

This process involves the formulation of physical mixture of a active ingredients and a water soluble carrier and heating it directly until it melted. The melted mixture is then solidified rapidly in an ice-bath under vigorous stirring. The final solid mass is crushed, pulverized and sieved. The modification in the method can be done by pouring the homogenous melt in the form of a thin layer onto a ferrite plate or a stainless steel plate and cooled by flowing air or water on the opposite side of the plate. In addition, a super-saturation of a solute or drug in a system can often be obtained by quenching the melt rapidly from a high temperature. Under such conditions, the solute molecule is arrested in the solvent matrix by the instantaneous solidification process. The quenching technique gives a much finer dispersion of crystallites when used for simple eutectic mixtures $^{32,}$. Advantage of melting method is that it is economic and solventless process, however this method is not suitable for the drug or carrier which is unstable at fusion temperature or evaporates at higher temperature.

\section{Solvent evaporation method}

In this method, the physical mixture of the drug and carrier is dissolved in a common solvent, which is evaporated until a clear, solvent free film is left. The film is further dried to constant weight. The main advantage of the solvent method is thermal decomposition of drugs or carriers can be prevented because of the relatively low temperatures required for the evaporation of organic solvents ${ }^{34}$.

\section{CHARACTERIZATION OF SOLID DISPERSIONS}

Different molecular structures of the drug in the matrix can be encountered in solid dispersions. Many techniques have been available to investigate the molecular arrangement in solid dispersions. However, most effort has been put into differentiate between amorphous and crystalline material. Many techniques are available which detect the amount of crystalline material in the dispersion ${ }^{35}$

\section{Drug -carrier miscibility:}

It is carried out by DSC, X-ray diffraction ${ }^{36}$ and NMR 1H Spin lattice relaxation time

\section{Drug carrier interactions:}

It is carried out by FT-IR spectroscopy, Solid state NMR and Raman spectroscopy

\section{Physical Structure:}

It characterized by following techniques;

Surface area analysis

Surface properties

Scanning electron microscopy

Dynamic vapor sorption

Raman microscopy

Inverse gas chromatography

\section{Amorphous content:}

This study performed by the DSC, Powder X-ray diffraction, Polarised light optical microscopy and Hot stage microscopy

\section{Dissolution enhancement ${ }^{37}$ :}

Solubility enhancement by the solid dispersion was examined by help of following parameters;

- Dissolution

- Intrinsic dissolution

- Dynamic solubility

- Dissolution in bio-relevant media

\section{Temperature Modulated Differential Scanning} Calorimetry (TMDSC)

Temperature Modulated Differential Scanning Calorimetry (TMDSC) can be used to assess the degree of mixing of an incorporated drug. ${ }^{38}$

Stability:

Stability of the solid dispersion was studied by Isothermal Calorimetry, DSC (Tg, Temperature recrystallization) and Saturated solubility studies

\section{Water vapour sorption}

Water vapour sorption can be used to discriminate between amorphous and crystalline material when the hygroscopicity is different. This method requires accurate data on the hygroscopicity of both completely crystalline and completely amorphous samples. ${ }^{39}$

\section{Isothermal Microcalorimetry}

Isothermal microcalorimetry measures the crystallization energy of amorphous material that is heated above its glass transition temperature $(\mathrm{Tg})$. This technique has some limitations. Firstly, this technique can only be applied if the physical stability is such that only during the measurement crystallization takes place. Secondly, it has to be assumed that all amorphous material crystallizes. ${ }^{\mathbf{4 0}}$ 


\section{APPLICATIONS OF SOLID DISPERSION ${ }^{41,42}$}

Solid dispersion systems can provide numerous additional benefits; some of them are as follows:

1. To increase the solubility of poorly soluble drugs thereby increase the dissolution rate, absorption and bioavailability.

2. To stabilize unstable drugs against hydrolysis, oxidation, recrimination, isomerization, photo-oxidation and other decomposition procedures.

3. To reduce a side effect of certain drugs.

4. Masking of unpleasant taste and smell of drugs.

5. Improvement of drug release from ointment creams and gels.

6. To avoid undesirable incompatibilities.

7. To obtain a homogeneous distribution of a small amount of drug in solid state.

8. To dispense liquid (up to $10 \%$ ) or gaseous compounds in a solid dosage.

9. To formulate a fast release primary dose in a sustained released dosage form.

\section{REFERENCES}

1. Leuner C, Dressman J. Improving drug solubility for oral delivery using solid dispersions. Eur J Pharm Biopharm 2000; 50:47-60.. I

2. Dalvi P., Gerange A., Ingale P. Solid dispersion: strategy to enhance solubility. Journal of Drug Delivery and

Therapeutics, 2015; 5(2):20-28. https://doi.org/10.22270/jddt.v5i2.1060NT

3. Nokhodchi A, Javadzadeh Y, Siahi-Shadbad MR, BarzegarJalali M. The effect of type and concentration of vehicles on the dissolution rate of a poorly soluble drug (indomethacin) from liquisolid compacts. J Pharm Pharm Sci 2005;8:18-25.R

4. Bhirud Y., Phalak H. Advances in solid dispersion technology and its applications in the development of solid dosage forms. Journal of Drug Delivery and Therapeutics, 2016; 6(6):40-47. https://doi.org/10.22270/jddt.v6i6.1316

5. Zoghbi A., Wang B. Carvedilol solubility enhancement by inclusion complexation and solid dispersion: review. Journal of Drug Delivery and Therapeutics, 2015; 5(2):1-8. https://doi.org/10.22270/jddt.v5i2.1074

6. Khan AD, Singh L, Various techniques of bioavailability enhancement: a review, Journal of Drug Delivery \& Therapeutics. 2016; 6(3):34-41. https://doi.org/10.22270/jddt.v6i3.1228

7. Dhirendra K. Solid dispersions: A review. Pak J Pharm Sci 2009; 22(2):234-246.

8. Doney J, Yang J, Baer H, Draganoiu E. Excipients in polymeric Drug Delivery and formulations. Pharm Tech. 2008:96-98.

9. Kerns EH, Li D. Drug-like properties: Concepts, structure, design and methods from ADME to toxicity optimization. Academic Press. 2008: 461

10. Kalyanwat R, Patel S. Solid dispersion: A method for enhancing drug dissolution International Journal of Drug Formulation \& Research. Nov-Dec. 2010, Vol. 1 (iii):1-14.

11. Chiou WL, Riegelman S. Pharmaceutical application of solid dispersion system. J Pharm Sci 1971; 60:1281-1302.

12. Janssens S, de Armas HN, D'Autry W, Van Schepdael A, Van den Mooter G, Characterization of ternary solid dispersions of Itraconazole in polyethylene glycol 6000/polyvidonevinylacetate 64 blends, European journal of pharmaceutics and biopharmaceutics, 2008, 69(3), 1114-20.
10. To formulate sustained release regimen of soluble drugs by using poorly soluble or insoluble carriers.

11. To reduce pre-systemic inactivation of drugs like morphine and progesterone

\section{CONCLUSION}

The enhancement solubility of poorly water soluble drugs remains one of the most challenging aspects of drug development. Solubilization of drug is the rate determining step for oral absorption of drugs, which can subsequently affect the in vivo absorption of drug. Because of solubility problem of many drugs the bioavailability of these gets affected and hence solubility enhancement becomes necessary. Solid dispersions are one of the most attractive processes to improve drug's poor water solubility. Various solubility enhancers like water-soluble carriers, co solvents, surfactants and superdisintegrants via solid dispersion approach (fusion method and solvent evaporation method) aids in solubility enhancement. These significantly help to improve the bioavailability and bioequivalence
13. Sareen S, Mathew G, Joseph L, Improvement in solubility of poor water-soluble drugs by solid dispersion, International journal of pharmaceutical investigation, 2012, 2(1), 12.

14. Sethia S, Squillante III E, Solid dispersions: revival with greater possibilities and applications in oral drug delivery, Critical Reviews ${ }^{\mathrm{TM}}$ in Therapeutic Drug Carrier Systems, 2003, 20(2\&3).

15. Vasconcelos T, Sarmento B, Costa P, Solid dispersions as strategy to improve oral bioavailability of poor water soluble drugs, Drug discovery today, 2007, 12(23), 1068-75.

16. Babu PS, Chowdary KPR. Enhancement of dissolution rate of celecoxib by solid dispersion in superdisintegrants. Ind Drugs. 2008; 45(7):547-552.

17. Kalyanwat R, Patel S. Solid dispersion: A method for enhancing drug dissolution. Int J Drug Form Res. 2010; 1(3): $1-14$

18. Sekiguchi K, Obi N. Studies on the absorption of eutectic mixture. I. A comparison of the behaviour of a eutectic mixture of sulfathiazole and that of ordinary sulfathiazole in man. Chem Pharm Bull 1961;9:866-72.

19. Goldberg AH, Gibaldi M, Kanig JL. Increasing dissolution rates and gastrointestinal absorption of drugs via solid solutions and eutectic mixtures II-experimental evaluation of a eutectic mixture: urea-acetaminophen system. J PharmaSci 1966;55:482-7.

20. Castellan GW. Physical Chemistry, Addison-Wesley, Menlo Park, CA; 1983. p. 324-36.

21. Swarbrick J. ed 3. Encyclopaedia of pharmaceutical technology; 2006. p. 775-7.

22. Goldberg AH, Gibaldi M, Kanig JL. Increasing dissolution rates and gastrointestinal absorption of drugs via solid solutions and eutectic mixtures. I. Theoretical considerations and discussion of the literature. J Pharm Sci 1965;54:1145-8.

23. Hume Rotherly W, Raynor GV. The structure of metals and alloys, Institute of Metals, London; 1954.

24. Argade PS, Magar DD, Saudagar RB. Review article on solid dispersion as solubility enhancement technique for poorly water soluble drugs. J Adv Pharm Edu Res 2013;3:427-39.

25. Verma S., Patel U., Patel R. Formulation and evaluation of ivermectin solid dispersion. Journal of Drug Delivery and 
Therapeutics, 2017; 7(7):15-17. https://doi.org/10.22270/jddt.v7i7.1572

26. Modi A, Tayade P, Enhancement of dissolution profile by solid dispersion (kneading) technique, AAPS PharmSciTech, 2006, 7(3), E87-E92

27. Patel MM, Patel DM. Fast dissolving valdecoxib tablets containing solid dispersion of valdecoxib. Ind J Pharm Sci. 2006: 222-225.

28. Bakatselou V, Oppenheim RC, Dressman JB. Solubilization and wetting effects of bile salts on the dissolution of steroids. Pharm Res, 1991; 8:1461-9.

29. Al-Marzouqi AH, Jobe B, Dowaidar A, Maestrelli F, Mura P, Evaluation of supercritical fluid technology as preparative technique of benzocaine-cyclodextrin complexesComparison with conventional methods, Journal of pharmaceutical and biomedical analysis, 2007; 43(2):566-74.

30. Nokhodchi A, Talari R, Valizadeh H, Jalali MB. An Investigation on the Solid Dispersions of Chlordiazepoxide. International Journal of Biomedical Science 2007; 3(3):21016.

31. Bhise SB, Rajkumar M. Effect of HPMC on Solubility and Dissolution of Carbamazepine Form III in Simulated Gastrointestinal Fluids. Asian Journal of Pharmaceutics 2008; 2(1):38-42.

32. Goldberg A, Gibaldi M, Kanig JL. Increasing dissolution rates and gastrointestinal absorption of drugs via solid solutions and eutectic mixtures III - experimental evaluation of griseofulvinsuccinic acid solid solution. J Pharm Sci. 1966; 55:487-492.

33. Kalaiselvan R, Mohanta GP, Manna PK, Manavalan R. Studies on mechanism of enhanced dissolution of albendazole solid dispersions with crystalline carriers. Ind J Pharm Sci. 2006; 68:599-607.
34. Serajuddin A., Solid dispersion technique. J. Pharmaceut. Sci., 1999; 88(10):891-900.

35. Kaushal A.M, Guptam P., Bansal AK., Amorphous drug delivery systems: molecular aspects, design, and performance. Crit. Rev. There. Drug Carrier Syst., 2004; 21(3):133-193.

36. Taylor L.S., Zografi G., Spectroscopic characterization of interactions between PVP and indomethacin in amorphous molecular dispersions. Pharmaceut. Res., 1997; 14:1691-1698.

37. Cilurzo F., Minghetti P., Casiraghi A., Montanari L., Characterization of nifedipine solid dispersions. Int. J. Pharmaceut., 2002; 242(1-2):313-317.

38. Pikal M.J., Lukes A.L., Lang J.E., Gaines K. Quantitative crystallinity determinations for beta-lactam antibiotics by solution calorimetry: correlations with stability. J. Pharmaceut. Sci., 1978; 67(6):767-73.

39. Buckton G., Darcy P., The use of gravimetric studies to assess the degree of crystallinity of predominantly crystalline powders. Int. J. Pharmaceut., 1995; 123:265-271.

40. Sebhatu T., Angberg M., Ahlneck C., Assessment of the degree of disorder in crystalline solids by isothermal microcalorimetry. Int, J. Pharmaceut., 1995; 104:135-144.

41. Shende M., Fiske P. Fabrication and optimization of novel glipizide sustained release matrices for solubility and dissolution enhancement by solid dispersion through hydrophillic carriers. Journal of Drug Delivery and Therapeutics, 2017; 7(6):38-48. https://doi.org/10.22270/jddt.v7i6.1538

42. Nagasamy V.D.RA., Saraswathi S., Padma Priya M., Khan N. I., Kathirulla N., Sruthi S. Dissolution enhancement of diacerein using water soluble carrier by solid dispersion technology. Journal of Drug Delivery and Therapeutics, 2017; 7(5):33-41. https://doi.org/10.22270/jddt.v7i5.1503 